This item was submitted to Loughborough's Research Repository by the author.

Items in Figshare are protected by copyright, with all rights reserved, unless otherwise indicated.

\title{
Addressing skin abrasions on artificial turfs with zwitterionic polymer brushes
}

PLEASE CITE THE PUBLISHED VERSION

http://dx.doi.org/10.1039/C5RA26194E

PUBLISHER

(c) The Royal Society of Chemistry

VERSION

AM (Accepted Manuscript)

\section{PUBLISHER STATEMENT}

This work is made available according to the conditions of the Creative Commons Attribution-NonCommercialNoDerivatives 4.0 International (CC BY-NC-ND 4.0) licence. Full details of this licence are available at: https://creativecommons.org/licenses/by-nc-nd/4.0/

\section{LICENCE}

CC BY-NC-ND 4.0

\section{REPOSITORY RECORD}

Tay, Sock P., Paul Fleming, Steph Forrester, and Xiao Hu. 2019. "Addressing Skin Abrasions on Artificial Turfs with Zwitterionic Polymer Brushes". figshare. https://hdl.handle.net/2134/21128. 


\title{
Journal Name
}

\section{ARTICLE}

\section{Addressing Skin Abrasions on Artificial Turfs with Zwitterionic Polymer Brushes}

Received 00th January 20xx, Accepted 00th January 20xx

DOI: $10.1039 / \times 0 \times x 00000 x$

www.rsc.org/

\author{
S. P. Tay, ${ }^{a, b}$ P. Fleming, ${ }^{a, c}$ S. Forrester ${ }^{a, d}$ and X. Hu ${ }^{a, b, *}$
}

To address the skin-friendliness of synthetic surfaces intended for sports applications, the frictional properties of hydrated zwitterionic polymer brushes is investigated outside of the common aqueous environment where an excess of lubricating water molecules is absent. Photo-grafted poly(sulfobetaine methacrylate) (pSBMA) brushes of various irradiation durations are prepared on polypropylene substrates and the improvement in frictional properties of the pSBMA-modified surfaces against a silicone skin counter-surface is studied. Frictional measurements under both dry and hydrated surface conditions shows that the applied surface modification was capable of forming a stable lubrication layer in the absence of excess water, significantly reducing the coefficient of friction by up to $78.8 \%$. The pSBMA brushes also provide the additional advantage of antifouling - exhibiting resistance towards pathogenic Staphylococcus aureus with almost zero surface colonization for samples irradiated for $1200 \mathrm{~s}$. The low skin-sample friction under ambient conditions and desirable fouling-resistance highlights the potential of pSBMA brushes as a modification strategy for achieving skin-friendly surfaces targeted at reducing the of skin abrasions.

\section{Introduction}

The skin is our largest organ - acting as a protective barrier for the human body. It is in perpetual interaction with surrounding surfaces, providing first-hand assessments of surface properties such as roughness, temperature and hardness. Hence, it is also the most susceptible to injuries inflicted by these surfaces, being exposed to the risks of abrasion, burns and bruises. A key aspect in consumer product development is the comfort of use and it is therefore important that attention be given to the designing of skin-product interfaces, to achieve tribological functionality while being conducive to the skin. Overlooking this may result in undesirable skin conditions such as friction blisters, ${ }^{1}$ diaper rash, ${ }^{2}$ airbag lesions, ${ }^{3}$ turf burns ${ }^{1,4,5}$ and dermatological infections. ${ }^{6,7}$

This research is part of a larger aim to address the issue of turf burns, where high injury rates of skin abrasion ${ }^{8-10}$ (Figure 1) have been reported from the use of artificial turf surfaces for sports such as football and rugby. Despite half a decade-worth

\footnotetext{
a. School of Materials Science and Engineering. Nanyang Technological University, 50 Nanyang Avenue, Block N4.1, S639798. Singapore.

${ }^{b .}$ Institute for Sports Research. Nanyang Technological University, 50 Nanyang Avenue, N3.1-B1a-01, S639798. Singapore.

c. School of Civil and Building Engineering. Loughborough University, LE11 3TU, Leicestershire, United Kingdom.

d. Wolfson School of Mechanical and Manufacturing Engineering. Loughborough University, LE11 3TU, Leicestershire, United Kingdom.

† Footnotes relating to the title and/or authors should appear here.

Electronic Supplementary Information (ESI) available: [details of any supplementary information available should be included here]. See
} DOI: $10.1039 / x 0 x x 00000 x$ of product development and innovation since its first introduction in the 1960s, there has been little advances to address the higher rates of skin abrasions recorded on artificial turf surfaces, apart from the adoption of softer polyolefins (polyethylene and polypropylene) for turf yarn manufacturing in the 1970 s to replace the stiff, abrasive polyamide fibres. ${ }^{11}$ The negative product image, together with the higher reported skin abrasion rates, have also affected players' acceptance of artificial turfs ${ }^{12,13}$ - countering efforts to promote the product as a sustainable playing surface. In addition, the presence of abrasions or open wounds act as a point of entry for bacteria ${ }^{6}$ where independent studies by Begier et al. ${ }^{14}$ and Kazakova et al. ${ }^{15}$ have related cases of bacterial-infection in players to turf burns resulting from abrasive artificial turf surfaces. Therefore, development of materials with integrated properties of improved friction and antibacterial-adhesion can be of great potential in improving the skin-turf interface for a truly "skinfriendly" product.

The strategy for material surface modification via grafted polymer brushes was inspired by work done on artificial hip joints used in the biomedical industry. Biocompatible poly(2methacryloyloxyethyl phosphorylcholine) (pMPC) brushes were grafted onto sample hip implants with the objective of reducing the effect of periprosthetic osteolysis - the loss of bone surrounding prosthesis implants due to excessive wear. $^{16,17}$ The solvated PMPC brushes provided excellent lubrication of the joint implant, with friction coefficients $(\mu)$ lowered from $\sim 0.8$ to $\sim 0.1$ and a reduction of wear up to forty times that of unmodified substrates. Zwitterionic polymer brushes are popularly studied for their lubrication effect in 
biomedical applications due to their exceptional hydrophilicity and antifouling nature. However, the excellent frictional properties of such brushes have largely been achieved under well-solvated conditions where the grafted samples were tested while fully submerged in good solvents. ${ }^{18-21}$ Under such conditions, the well-solvated brushes in the presence of excess lubricant result in repulsive forces that separate the interacting surfaces, reducing interfacial resistance and hence effective lubrication.

For applications outside of the human body, it is important to consider the environment surrounding the frictional contacts many of which are exposed to ambient conditions hence limiting the abundance of solvent molecules available for the hydration lubrication. In the case of player-turf interactions, the fibre-skin interface exists in an ambient surrounding with the presence of occasional but limited hydration when the artificial playing surfaces are watered prior to use $\mathrm{e}^{22,23}$ - where a sub-surface drainage system prevents the turf fibres from being submerged. Additionally, material improvement or modification is limited to only one of the interacting surfaces such as for artificial turf fibres which requires optimal friction properties when in contact with the human skin. The complexity of frictional mechanisms occurring at the skin-turf interface cannot be correlated to systems where the countersurface used is of non-skin-like materials such as glass ${ }^{24}$ or steel $^{25}$. While the lubricating effect of zwitterionic polymer brushes have been extensively studied, there has yet to be available data for the frictional assessment of such surfaces using skin-like materials, under mildly hydrated conditions to simulate real-life settings.

The focus of this study is therefore to explore the surface modification of a real substrate (polypropylene (PP)) using zwitterionic polymers to create potentially skin-friendly surfaces. The samples are then tested for their frictional interaction with skin-like test surfaces in a first attempt to assess the skin-friendliness of polymer brush-modified samples using an industry-accepted ${ }^{26}$ skin model, subjected to realistic usage conditions. Surface grafting was selected as the approach to prepare the desired skin-surface interface due to minimal effect on the bulk mechanical properties of the substrate material ${ }^{27,28}$ which may have already been optimized for its end application.

In this paper, commercially available polypropylene films were modified with poly(sulfobetaine methacrylate) (pSBMA) brushes via photoinduced grafting - a strategy chosen based on the advantages of fast reaction rate, low production cost and ease of scalability for integration into manufacturing processes. ${ }^{27,29}$ Although studies regarding swelling-induced detachment of polymer grafts have been reported ${ }^{30-33}$, the stability and robustness of the surface-grafted pSBMA brushes in this study will not be compromised under the ambient, nonsubmerged conditions in the intended application environment of an artificial turf surface.
The effect of irradiation duration on the grafting extent was investigated by gravimetric analysis and characterization of surface hydrophilicity, chemical composition and surface morphology. The identity of the surface bound water was also determined by differential scanning calorimetry. Skin-surface frictional behaviour was assessed for both dry and hydrated pSBMA brushes under ambient conditions, using a pin-on-disk microtribometer with an attached skin-equivalent silicone skin tip, to measure the effect of hydration lubrication ${ }^{34}$ of the superhydrophillic PSBMA brushes. As a well-known advantage of PSBMA, the antifouling properties were evaluated by conducting a bioassay against Gram-positive Staphylococcus aureus (S. aureus) to investigate the susceptibility of the samples to the bacterial adhesion and colonization.

\section{Experimental}

\section{Photoinduced Surface Grafting of Polypropylene}

Commercial PP films of $0.03 \mathrm{~mm}$ thickness were purchased from Goodfellow Inc. of Cambridge, UK and cut into $0.3 \mathrm{~cm}$ by $2.5 \mathrm{~cm}$ samples. The samples were cleaned by sonication with acetone for three repetitions to remove any residual organic contaminants and allowed to dry at room temperature. Sulfobetaine methacrylate (SBMA) monomer was purchased from Sigma-Aldrich together with photoinitiator benzophenone (BP). All other solvents were used as received.

Surface grafting of poly-SBMA onto the PP substrates was carried out using the Incure F200P UV Flood Curing Lamp equipped with a metal halide lamp $(600 \mathrm{~W})$ at an irradiation intensity of $50 \mathrm{~mW} / \mathrm{cm}^{2}\left( \pm 5 \mathrm{~mW} / \mathrm{cm}^{2}\right)$. The surface grafting experiments were adapted from the approach used by Yang and Ranby. ${ }^{35-38}$ The PP substrates were submerged in a $10 \mathrm{wt} \%$ $\mathrm{BP}$ solution for $30 \mathrm{~min}$ and were then removed and allowed to dry in the dark for $4 \mathrm{~h}$. The zwitterionic monomer solution of $0.2 \mathrm{M}$ was prepared by dissolving SBMA in degassed deionized water. A drop of SBMA solution was then deposited onto the BP-coated substrate using a micropipette and a clean PP film was placed on top of the drop, forming a sandwich structure with a uniform liquid layer between the two films. The assembled structure was then placed in an enclosed chamber with the ultraviolet (UV) source irradiating the surface at right angles. Poly-SBMA (pSBMA) growth via grafting-from proceeded according to Scheme 1 . The extent of polymerization was varied by using irradiation durations of $300,600,900$ and $1200 \mathrm{~s}$.

After grafting, the modified PP samples were washed in a hot deionized water bath to remove residual monomers and homopolymers formed as a side product in the reaction. The washed samples were then dried in vacuo overnight and stored in desiccators for further characterization. The grafting density of the modified samples was quantified by gravimetric analysis where the difference in initial PP substrate and final dry masses was determined and expressed as a gain in grafted 
mass per area. Five samples were prepared for each irradiation duration.

\section{Material Characterization}

The poly-SBMA-grafted PP (pSBMA-g-PP) samples were characterized by Fourier Transform Infrared SpectroscopyAttenuated Total Reflectance (FTIR-ATR) using the Perkin Elmer Frontier to detect the presence of key functional groups on the sample surfaces. Scanning was carried out from 4000 $\mathrm{cm}^{-1}$ to $650 \mathrm{~cm}^{-1}$ for 16 scans with a resolution of $2 \mathrm{~cm}^{-1}$. Analysis of surface elemental composition was carried out using X-ray Photoelectron Spectroscopy (XPS) (AXIS Supra, Kratos Analytical Ltd, UK). The samples were mounted onto a glass slide and analysis was performed using a monochromatic Al $\mathrm{K} \alpha$ excitation source ( $\mathrm{hu}=1486.71 \mathrm{eV}$, nominal operating voltage of $15 \mathrm{kV}$ ). A survey scan was carried out from 1200 to 0 $\mathrm{eV}$ with subsequent corresponding region scans for the identified elements. XPS data analysis was performed using the CasaXPS Version 2.3.15 software.

The static water contact angles were measured using Analytical Technologies FTA32, with at least three repeated readings per sample. The sample surfaces were imaged with Field Emission Scanning Electron Microscopy (JEOL JSM$6340 \mathrm{~F}$ ), at an accelerating voltage of $5 \mathrm{kV}$. Surface roughness of the pSBMA-g-PP samples were also investigated via tapping mode Atomic Force Microscopy (AFM) (Digital Instruments DI3100 ) at a scanning rate of $1.25 \mathrm{~Hz}$ with a monolithic aluminium-coated silicon probe.

Differential Scanning Calorimetry (DSC) measurements were conducted on the hydrated samples using TA Instruments Q10 for the characterization of the states of water bounded onto the pSBMA-g-PP surfaces. ${ }^{39,40}$ The samples were cut to size and equilibrated in deionized water for $24 \mathrm{~h}$. Prior to testing, excess surface water was removed using filter paper. The hydrated samples were immediately sealed in pre-weighed hermetic pans. The analysis was carried out at a cooling rate of $2.5^{\circ} \mathrm{C} / \mathrm{min}$ to $-60{ }^{\circ} \mathrm{C}$, held isothermal for $2 \mathrm{~min}$, and then heated at a rate of $2.5^{\circ} \mathrm{C} / \mathrm{min}$ to $60^{\circ} \mathrm{C}$. The TA Universal Analysis software was used to determine the transition enthalpy $(\Delta H)$ of the melting of frozen water. After the DSC runs, the pans were punctured and dried in an oven at $120^{\circ} \mathrm{C}$ overnight to ensure complete drying. The mass difference between the pre-DSC and post-drying sealed pans gives the total water content $(\mathrm{Mw})$ of each sample; while the amount of freezable water (Mf) was calculated from the $\Delta H$ values (assuming the latent heat of fusion of water $=-334.45 \mathrm{~J} / \mathrm{g}$ ). ${ }^{39}$ The amount of non-freezable water $\left(\mathrm{M}_{\mathrm{nf}}\right)$ was then calculated by subtracting $M_{f}$ from $M_{w}$. The DSC trials were repeated at least twice.

\section{Friction Studies}

The coefficient of friction $(\mu)$ of the samples were studied using CSM Instruments Microtribometer with $1 \mathrm{~cm}$-diameter round tips of $\mathbf{L} 7350$ silicone skin, purchased from Maag
Technic AG, Switzerland. The silicone skin used is the FIFAapproved counter-surface for assessing skin friction of artificial turf surfaces in accordance to their Handbook of Test Methods for Football Turf. ${ }^{26}$ Frictional measurements were performed at room temperature with a normal load of $0.2 \mathrm{~N}$, rotational radius of $1.00 \mathrm{~mm}$ and a linear speed of $5 \mathrm{~cm} / \mathrm{s}$ for 300 cycles. The samples of varying grafting extents, together with a PP control, were tested under both dry and hydrated states where the hydrated samples were submerged in deionized water for $2 \mathrm{~h}$ and excess surface moisture removed using a piece of filter paper prior to the frictional studies.

\section{Antifouling Bioassay against Staphylococcus aureus}

Gram positive $S$. aureus was used to evaluate the antifouling properties of the pSBMA-g-PP samples, in accordance to common assay procedures. ${ }^{41,42}$ The $S$. aureus cells were cultured in tryptic soy broth at $37^{\circ} \mathrm{C}$ overnight and the suspension was centrifuged to remove the supernatant. The cells were then re-suspended in phosphate-buffered saline (PBS) to a concentration of $10^{8}$ cells $/ \mathrm{mL}$. PBS-pre-soaked pSBMA-g-PP samples and PP controls were immersed the bacteria suspension $(2 \mathrm{~mL})$ at room temperature for $4 \mathrm{~h}$ and repeatedly rinsed with PBS subsequently - to remove nonadsorbed cells. The adhered bacteria cells were fixated with $2.5 \%$ glutaraldehyde followed by $1 \%$ sodium cacodylate and dehydrated with serial ethanol solutions, and then imaged using FESEM. ${ }^{43,44}$ The images were further processed using imaging software ImageJ to semi-quantify the antifouling properties of the surfaces.

\section{Results and Discussion}

\section{Surface Modification of Polypropylene with pSBMA}

Gravimetric analysis of the grafting process shows an increase in mass gained per unit area with irradiation duration. Samples irradiated for $1200 \mathrm{~s}$ showed the highest grafting density of $0.284 \pm 0.018 \mathrm{mg} / \mathrm{cm}^{2}$, as presented in Figure 2 .

The increase in sample mass is attributed to the successful grafting of pSBMA brushes via the graft-from process of photoinduced free radical polymerization. Figure $\mathbf{3}$ shows the FTIRATR spectra of the pristine PP substrate and PSBMA-g-PP samples of increasing grafting extent. The spectrum of the grafted samples detected the characteristic peaks $\left(\mathrm{cm}^{-1}\right)$ at 751 (CS), 1043 (SO) and 1722 (COO), indicating the presence of pSBMA on the sample surfaces. Semi-quantitative analysis of the relative intensity of characteristic SO peaks against reference $\mathrm{CH}$ stretching peaks show the increase in presence of SO groups (inset of Figure $\mathbf{3}$ ) - indicating higher grafting extents with increased UV-exposure times. Wide $\mathrm{OH}$ stretching peaks appeared at $3445 \mathrm{~cm}^{-1}$ for highly grafted PP samples (irradiation duration $900 \mathrm{~s}$ and $1200 \mathrm{~s}$ ), signifying the presence of surface hydration. The detection of the $\mathrm{OH}$ peaks suggests that the modified surfaces were capable of binding atmospheric water, which is characteristic of hydrophilic SBMA polymers. 
XPS results (Supplementary Information, Figure S1) provided further information regarding the chemical composition of the modified substrates. The spectrum obtained from the modified samples (Figure S1 ii - v) confirmed the surface grafting of pSBMA brushes with presence of the $\mathrm{S} 2 \mathrm{p}(168.0 \mathrm{eV})$ and $\mathrm{N} 1 \mathrm{~s}$ $(402.9 \mathrm{eV})$ emission peaks. Deconvolution of the high resolution region scans also identified chemical functionalities equivalent to those present in pSBMA with the $C 1$ s core-level spectrums showing 4 peaks corresponding to the groups of $\mathrm{O}-$ $\mathrm{C}=\mathrm{O}(289.3 \mathrm{eV}), \mathrm{C}-\mathrm{O}(286.9 \mathrm{eV}), \mathrm{C}-\mathrm{N}(285.8 \mathrm{eV})$ and C $-\mathrm{C}(285.0$ $\mathrm{eV})$ respectively. ${ }^{45-47}$ With increasing irradiation duration, the intensity of the $\mathrm{O}-\mathrm{C}=\mathrm{O}, \mathrm{C}-\mathrm{O}$ and $\mathrm{C}-\mathrm{N}$ peaks identified in the $\mathrm{C}$ $1 \mathrm{~s}$ core-level spectrums increase, indicating a higher concentration of pSBMA present at the surface level. The 1:1 ratio of $N$ 1s and $S 2 p$ detected on the modified samples surfaces (Figure S1 vi) confirms the chemical identity of PSBMA while the increased concentrations reiterates the increased grafting with irradiation duration.

The hydrophilicities of the modified surfaces were further validated with the decrease in water contact angle from $90.0^{\circ}$ $\left( \pm 2^{\circ}\right)$ for pristine PP substrate to $22.0^{\circ}\left( \pm 3^{\circ}\right)$ for pSBMA-g-PP irradiated for $1200 \mathrm{~s}$. The sample surface remains hydrophobic $\left(83.0 \pm 3^{\circ}\right)$ after $300 \mathrm{~s}$ of UV-grafting, implying insufficient surface modification. The measured contact angles give an indication of the extent of surface grafting, with the trend in decreasing contact angle tapering off at $1200 \mathrm{~s}$ of irradiation signifying complete saturation of the substrate surface with polymer brushes which was further validated by FESEM imaging.

From the FESEM images (Figure 4), the formation of the polymer brushes can be seen as globules on the sample surfaces, with increasing surface coverage from $300 \mathrm{~s}$ to $1200 \mathrm{~s}$ of irradiation duration. Complete surface coverage was achieved for samples irradiated for $1200 \mathrm{~s}$, with polymer brush globules of approximately $200 \mathrm{~nm}$ in diameter. The hydrophilic polymer brushes coil up to assume globular structures when characterized under dry conditions as a result of the strong interactions between intra-chain zwitterionic functional groups. The globule size increases with UV-exposure indicating the formation of longer polymer brushes; observed from the corresponding AFM images (Figure 5) where the dried topography shows globules sizes of up to $17 \mathrm{~nm}$ in height as seen from the cross-sectional profiles, similar to that of the polymer brushes grafted in works by Kobayashi et al. ${ }^{48}$ and Nomura et al. ${ }^{49}$, intended for interfacial lubrication. The variation of grafting duration showed that as the time allowed for polymerization was increased, the covalently tethered pSBMA brushes grew in length as well as in surface coverage; rendering the hydrophobic substrate surface a hydrophilic nature.

The DSC studies showed an increasing amount of water absorbed with increasing pSMBA grafting, from the endothermic melting peaks shown in Figure 6 . There was no peak detection for the pure PP substrate which implies the extremely low concentration of water absorbed by the sample during equilibration, such that the sporadically-spaced water molecules were unable to congregate to form ice crystals in the cooling step. This reaffirms the low polymer-water affinity of hydrophobic PP. With increasing PSBMA grafting, the total amount of non-freezable water (as a percentage of total water absorbed) increases from $2.35 \%$ to $15.6 \%$ for samples irradiated for $300 \mathrm{~s}$ and $1200 \mathrm{~s}$ respectively (inset of Figure 6). The presence of non-freezable water suggests that during the hydration process, water molecules bind strongly to the pSBMA brushes, resulting in capillary condensation - an effect that restricts the phase transition of the bound water even at low temperatures. ${ }^{40,50}$ The strong interaction of SBMA entities with water molecules is a key characteristic of zwitterionic polymers, allowing the formation of a hydration layer that is stabilized by the tethered polymer brushes. This strongly held hydration is often credited for the lubricating and antifouling properties of PSBMA brushes, ${ }^{18,51,52}$ as further discussed in the subsequent sections.

\section{Frictional Property of pSBMA-g-PP}

The abrasiveness of a surface can be related to its frictional interaction with skin. Excessive friction may lead to the removal of superficial epidermal cells ${ }^{5}$ and/or lesion of the epidermis to expose underlying tissue. ${ }^{1,4,53}$ In addition to discomfort and bleeding, the abrasion wounds act as points of entry for bacterial infection ${ }^{6}$, leading to further complications. pSBMA brushes were hence grafted with the intention to modify the frictional properties of PP.

The frictional studies were designed as a bench-top test to investigate the skin-friendliness of the modified substrates, instead of in vivo testing using live subjects due to ethical considerations and the inconsistency of skin tribological results. ${ }^{54-58}$ The FIFA-approved L7350 silicone skin was selected as a standard counter-surface for the frictional measurements as it is currently used by the football governing body in testing skin abrasiveness of large-scale artificial turf systems. Furthermore, silicone is commonly used in the manufacturing of skin surrogates and has the highest replication of skin properties amongst commonly available materials, ${ }^{59}$ adding to the repeatability of the test method.

Under dry conditions, all samples exhibited high frictional values ( $\mu=1.08-1.37$ ) (unfilled columns in Figure 7 ). The frictional mechanism of interlocking asperities dominates with an observable increase in $\mu$ measured for samples with higher grafting extents. When in their dry states, the PSBMA brushes adopt globular structures that increase in size with irradiation duration (evident from the AFM morphologies in Figure 5), resulting in large asperities that provide resistance against the surface roughness of the silicone tribo-tips. In addition, the high friction is due to the significantly larger contact area $\left(\sim 3 \mathrm{~mm}^{2}\right.$, approximated using the JohnsonKendall-Roberts model of contact mechanics for adhesive 
elastic contacts) ${ }^{60}$ as compared to typical frictional studies using micron-scale apparatuses such as the AFM with colloidal probes (tip area of $7 \times 10^{-5} \mathrm{~mm}^{2}$ ) 61 or are measured under very small normal loads as in the case of the commonly used Surface Force Balance (SFB) $\left(\sim 10^{-3} \mathrm{~N}\right)^{51}$.

In the presence of surface hydration, friction was greatly reduced on the extensively-grafted PSBMA-g-PP samples $(\mu=$ 0.30 ) but remains relatively unchanged for the hydrophobic PP substrates and insufficiently-modified sample (UV-exposure of $300 \mathrm{~s})$ (Figure 7). These results are in line with that of Bongaerts et al. for soft contact tribo-pairs under the influence of water lubrication. Bongaerts et al. observed that the friction coefficients for hydrophobic-hydrophobic poly(dimethylsiloxane) (PDMS) tribo-pairs are similar (and consistently high; $\mu>1$ ) under both dry and hydrated conditions. ${ }^{62}$ This observation is reciprocated for the PP-L7350 tribo-pair in our study where most of the water is expelled under normal loading, as neither hydrophobic surface were capable of holding on to the hydration.

When one of the counter-surfaces was rendered hydrophilic properties through surface grafting of PSBMA, water that strongly binds to the polymer brushes result in the formation of a hydration layer. This non-compressible layer of water separates the asperities on the interacting surfaces, and acts as lubrication to reduce friction caused by asperity deformation and ploughing. ${ }^{20,63,64}$ Our results showed that modification with pSBMA was capable of reducing silicone skin-surface friction by up to $78.8 \%$ in the presence of surface hydration. This reduction in frictional value is significant when compared to the $\sim 40 \%$ decrease in $\mu$ achieved by Kobayashi et al. for PMPC brushes in dry and aqueous environments against a glass probe of similar dimensions. ${ }^{24}$ The low $\mu$ values of $\sim 0.30$ are also comparable with the coefficients of friction obtained by Minn et al. when studying hydration lubrication effect of PMMA brushes in an aqueous media using a rigid steel probe ${ }^{25}$ in which excess water is available for lubrication. The effect of reduced friction is also observed to increase with sample irradiation duration and consequently, brush thickness, as the amount of adsorbed hydrated layer increases with a larger quantity of hydrophilic sulfobetaine entities present on the sample surfaces.

\section{Resistance of pSBMA-g-PP to $S$. aureus}

The selected PSBMA brushes have been well studied for their antifouling properties. ${ }^{65-67}$ Antifouling is a critical property when addressing the skin-friendliness of surfaces as the contact of open wounds with bacteria and viruses on common surfaces may result in contamination and subsequent infections. To emphasize the skin-friendliness of our pSBMAmodified surfaces, pathogenic $S$. aureus was selected for the antifouling assay of the prepared pSBMA-g-PP samples due to its well-documented risk associated with infections ${ }^{68,69}$ and the prevalence of $S$. aureus incidents within the sporting community. ${ }^{7,14,70}$
It can be seen from Figure $\mathbf{8}$ that tethered pSBMA brushes are effective in preventing the cell adhesion of $S$. aureus. The antifouling properties of the modified surfaces improved dramatically with increased grafting density, achieving negligible bacteria adhesion ( $0.09 \%$ cell-surface coverage) for samples irradiated for longer than $900 \mathrm{~s}$ as compared to the $33.4 \%$ coverage on the PP control.

The antifouling property of pSBMA is commonly attributed to the capability of zwitterionic moieties to tightly bind water molecules - forming a barrier that prevents cell and protein access to the hydrophobic PP substrate. In order for the $S$. aureus cells to contact and subsequently colonize the sample surfaces, they will have to first expel the obstructing water molecules in the hydration layer - an energetically unfavorable process. $^{71,72}$ The strongly bound water molecules on the pSBMA consist largely of free water, similar to that surrounding the bacteria cells. ${ }^{52,73}$ This allows for the continuous exchange of the free water molecules between the fouling body and the modified surface (illustrated in Figure 5vi) without the bacteria having to lose any of their bound water molecules that may result in irreversible conformational changes to the cells, inducing adsorption. The hydrated pSBMA-grafted substrates hence allow the $S$. aureus cells to approach and withdraw with no stimulus for cell adsorption, leaving the surfaces resistant to fouling.

\section{Conclusions}

The effect of grafted-from zwitterionic pSBMA brushes as skinfriendly modification to abrasive artificial turf surfaces was investigated, by studying their frictional performances and antifouling properties. The affinity of the modified substrates to surface hydration provided a lubricating effect on the frictional interaction between the samples and $\mathbf{L} 7350$ silicone 'skin' used to simulate interaction with skin. Frictional measurements performed for the dry and hydrated samples under ambient conditions showed that the presence of surface water on the hydrophilic samples greatly reduced friction coefficients up to $78.8 \%$, with absolute values comparable to experiments conducted in submerged aqueous environments. These results are significant to the development of skinfriendly surfaces as frictional assessment was conducted under realistic application conditions while using appropriate counter surfaces. The grafted samples also exhibited superior antifouling properties, achieving almost zero $S$. aureus cell adhesion. This was attributed to the ability of the zwitterionic brushes to bind strongly to water molecules, forming a stable hydration layer that prevents the bacteria from accessing the susceptible hydrophobic substrate. This study showed that the hydration layer bound to zwitterionic PSBMA brushes is capable providing effective lubrication even in the absence of excess lubricant, presenting the potential of polymer-bound surface hydration in addressing issues of skin abrasion and skin infection under ambient operating conditions - providing a 
simple and practical strategy for the development of skinfriendly surfaces.

\section{Acknowledgements}

The authors would like to thank the Energy Research Institute, Nanyang Technological University (ERI@N) for kindly providing access to the microtribometer and the Facility for Analysis, Characterization, Testing and Simulation (FACTS) for providing access to the FESEM imaging equipment. Special thanks to $\mathrm{Dr}$ Ronn Goei from the Nanyang Environment and Water Research Institute (NEWRI) for helping with the XPS analysis. This study is part of a Ph. D. program under the Institute for Sports Research (ISR), Nanyang Technological University, Singapore.

\section{References}

G. Eiland and D. Ridley, J. Orthop. Sport. Phys. Ther., 1996, 23, 388-402.

G. N. Stamatas and N. K. Tierney, Pediatr. Dermatol., 2014 31, 1-7.

3 S. M. Duma, J. M. Cormier, W. J. Hurst, J. D. Stitzel and I. P. Herring, Proc. Inst. Mech. Eng. Part D J. Automob. Eng., 2011, 226, 468-478.

4 A. Metelitsa, B. Barankin and A. N. Lin, Int. J. Dermatol., 2004, 43, 113-119.

5 W. F. Bergfeld and J. S. Taylor, Am. J. Ind. Med., 1985, 8, 403-413.

6 M. Pecci, D. Comeau and V. Chawla, Am. J. Sports Med., 2009, 37, 406-418.

7 A. Grosset-Janin, X. Nicolas and A. Saraux, Médecine Mal. Infect., 2012, 42, 533-44.

8 M. C. Meyers and B. S. Barnhill, Am. J. Sports Med., 2004, 32, 1626-1638. C. W. Fuller, R. W. Dick, J. Corlette and R. Schmalz, Br. J. Sports Med., 2007, 41 Suppl 1, i27-32.

11 P. Fleming, Proc. Inst. Mech. Eng. Part P J. Sport. Eng. Techonology, 2011, 225, 43-62.

12 E. M. Zanetti, Appl. Ergon., 2009, 40, 485-490.

13 P. Burillo, L. Gallardo, J. L. Felipe and A. M. Gallardo, Eur. J. Sport Sci., 2014, 14, S437-S447.

14 E. M. Begier, K. Frenette, N. L. Barrett, P. Mshar, S. Petit, D. J. Boxrud, K. Watkins-Colwell, S. Wheeler, E. A. Cebelinski, A. Glennen, D. Nguyen and J. L. Hadler, Clin. Infect. Dis., 2004, 39, 1446-1453.

15 S. V Kazakova, J. C. Hageman, M. Matava, A. Srinivasan, L. Phelan, B. Garfinkel, T. Boo, S. McAllister, J. Anderson, B. Jensen, D. Dodson, D. Lonsway, L. K. McDougal, M. Arduino, V. J. Fraser, G. Killgore, F. C. Tenover, S. Cody and D. B. Jernigan, N. Engl. J. Med., 2005, 352, 468-475.

16 T. Moro, Y. Takatori, K. Ishihara, T. Konno, Y. Takigawa, T. Matsushita, U. Chung, K. Nakamura and H. Kawaguchi, Nat. Mater., 2004, 3, 829-836.
M. Kyomoto, T. Moro, T. Konno, H. Takadama, H. Kawaguchi, Y. Takatori, K. Nakamura, N. Yamawake and K. Ishihara, J. Mater. Sci. Mater. Med., 2007, 18, 1809-1815. T. Goda, T. Konno, M. Takai and K. Ishihara, Colloids Surfaces B Biointerfaces, 2007, 54, 67-73.

M. Chen, W. H. Briscoe, S. P. Armes and J. Klein, Science (80-. )., 2009, 323, 1698-1701.

A. Nomura, A. Goto, K. Ohno, E. Kayahara, S. Yamago and Y. Tsujii, J. Polym. Sci. Part A Polym. Chem., 2011, 49, 52845292.

O. Tairy, N. Kampf, M. J. Driver, S. P. Armes and J. Klein, Macromolecules, 2015, 48, 140-151.

A. J. McLeod, School of Applied Sciences, 2008.

K. Severn, Loughborough University, 2010.

M. Kobayashi, Y. Terayama, N. Hosaka, M. Kaido, A. Suzuki, N. Yamada, N. Torikai, K. Ishihara and A. Takahara, Soft Matter, 2007, 3, 740-746.

M. Minn, M. Kobayashi, H. Jinnai, H. Watanabe and A. Takahara, Tribol. Lett., 2014, 55, 121-129.

Fédération Internationale de Football Association (FIFA), FIFA Quality Concept for Football Turf - Handbook of Test Methods, 2012.

P. Y. Zhang and B. Ranby, J. Appl. Polym. Sci., 1990, 40, 1647-1661.

J. Deng, L. Wang, L. Liu and W. Yang, Prog. Polym. Sci., 2009, 156-193.

B. Ranby, Int. J. Adhes. Abrasives, 1999, 19, 337-343.

B. Lego, W. G. Skene and S. Giasson, Macromolecules, 2010, 43, 4384-4393.

K. Enomoto, S. Takahashi, T. Iwase, T. Yamashita and Y. Maekawa, J. Mater. Chem., 2011, 21, 9343.

K. Enomoto, S. Takahashi and Y. Maekawa, Macromol. Chem. Phys., 2012, 213, 72-78.

R. W. N. Nugroho, K. Odelius, A. Höglund and A.-C. Albertsson, J. Appl. Polym. Sci., 2015, 132, 42736. K. Ikeuchi, Proc. Inst. Mech. Eng. Part J J. Eng. Tribol., 2007, 221, 301-305.

W. T. Yang and B. Ranby, J. Appl. Polym. Sci., 1996, 62, 533-543.

W. T. Yang and B. Ranby, J. Appl. Polym. Sci., 1996, 62, 545-555.

W. T. Yang and B. Ranby, Polym. Bull., 1996, 37, 89-96. B. Ranby, W. T. Yang and O. Tretinnikov, Nucl. Instruments Methods Phys. Res. Sect. B Beam Interact. with Mater. Atoms, 1999, 151, 301-305.

F. M. Plieva, M. Karlsson, M.-R. Aguilar, D. Gomez, S. Mikhalovsky and I. Y. Galaev', Soft Matter, 2005, 1, 303309.

Z. H. Ping, Q. T. Nguyen, S. M. Chen, J. Q. Zhou and Y. D. Ding, Polymer (Guildf)., 2001, 42, 8461-8467.

X. Ding, C. Yang, T. P. Lim, L. Y. Hsu, A. C. Engler, J. L. Hedrick and Y.-Y. Yang, Biomaterials, 2012, 33, 6593-6603. M. Li, K. G. Neoh, L. Q. Xu, R. Wang, E. Kang, T. Lau, D. P. Olszyna and E. Chiong, Langmuir, 2012, 28, 16408-16422. P. Allan-Wojtas, L. Truelstrup Hansen and A. T. Paulson, LWT - Food Sci. Technol., 2008, 18, 101-108.

R. Lamed, J. Naimark, E. Morgenstern and E. a Bayer, J. 
Bacteriol., 1987, 169, 3792-3800.

45 Y. C. Chiang, Y. Chang, A. Higuchi, W. Y. Chen and R. C. Ruaan, J. Memb. Sci., 2009, 339, 151-159.

46 J. Yuan, Y. Yuan, J. Shen, S. Lin, W. Zhu and J. Fang, Chinese J. Polym. Sci., 2003, 21, 419-425.

47 Y. Jiang, B. Rongbing, T. Ling, S. Jian and L. Sicong, Colloids Surfaces B Biointerfaces, 2004, 36, 27-33.

48 M. Kobayashi, M. Terada and A. Takahara, in Design for Innovative Value Towards a Sustainable Society, Springer Netherlands, Dordrecht, 2012, vol. 2, pp. 901-904.

49 A. Nomura, K. Okayasu, K. Ohno, T. Fukuda and Y. Tsujii, Macromolecules, 2011, 44, 5013-5019.

50 T. Hatakeyma, H. Kasuga, M. Tanaka and H. Hatakeyama, Thermochim. Acta, 2007, 465, 59-66.

51 M. Chen, W. H. Briscoe, S. P. Armes, H. Cohen and J. Klein, Eur. Polym. J., 2011, 47, 511-523.

52 Y.-H. Zhao, K.-H. Wee and R. Bai, J. Memb. Sci., 2010, 362, 326-333.

53 R. S. W. Basler, C. M. Hunzeker and M. A. Garcia, Phys. Sportsmed., 2004, 32, 33-40.

54 N. Gitis and R. Sivamani, Tribol. Trans., 2004, 47, 461-469.

55 R. K. Sivamani and H. I. Maibach, Proc. Inst. Mech. Eng. Part J J. Eng. Tribol., 2006, 220, 729-737. S. Derler and L. C. Gerhardt, Tribol. Lett., 2012, 45, 1-27. A. F. El-Shimi, J. Soc. Cosmet. Chem., 1977, 28, 37-51.

58 C. Pailler-Mattei, S. Pavan, R. Vargiolu, F. Pirot, F. Falson and H. Zahouani, Wear, 2007, 263, 1038-1043.

59 M. Zhang and A. F. T. Mak, Prosthet. Orthot. Int., 1999, 23, 135-141.

60 V. L. Popov, Contact Mechanics and Friction, SpringerVerlag Berlin Heidelberg, 1st edn., 2010.

61 M. K. Vyas, K. Schneider, B. Nandan and M. Stamm, Soft Matter, 2008, 4, 1024-1032.

62 J. H. H. Bongaerts, K. Fourtouni and J. R. Stokes, Tribol. Int., 2007, 40, 1531-1542.

63 S. M. Hsu, Langmuir, 1996, 12, 4482-4485.

64 K. Fukazawa and K. Ishihara, Colloids Surfaces $B$ Biointerfaces, 2012, 97, 70-76.

65 Z. Zhang, S. Chen, Y. Chang and S. Jiang, J. Phys. Chem. B, 2006, 110, 10799-10804.

66 H. H. Tuson and D. B. Weibel, Soft Matter, 2013, 9, 4368.

67 Y. Zhang, Z. Wang, W. Lin, H. Sun, L. Wu and S. Chen, J. Memb. Sci., 2013, 446, 164-170.

68 J. N. Baumgartner, C. Z. Yang and S. L. Cooper, Biomaterials, 1997, 18, 831-7.

69 L. G. Harris, S. J. Foster and R. G. Richards, Eur. Cells Mater., 2002, 4, 39-60.

70 A. S. McNitt, Survival of Staphylococcus aureus on synthetic turf, 2008.

71 S. Chen, F. Yu, Q. Yu, Y. He and S. Jiang, Langmuir, 2006, 22, 8186-8191.

72 S. Chen, L. Li, C. Zhao and J. Zheng, Polymer (Guildf)., 2010, 51, 5283-5293.

73 K. Ishihara, H. Nomura, T. Mihara, K. Kurita, Y. Iwasaki and N. Nakabayashi, J. Biomed. Mater. Res., 1998, 39, 323-330. 


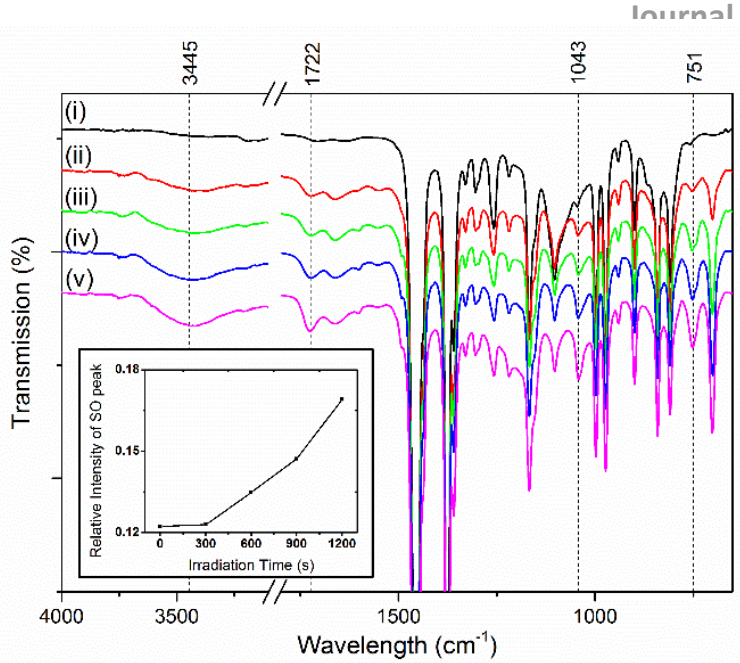

Figure 1. Epidemiological studies showing skin-related injuries as a percentage of the total number of injuries recorded, with higher rates of the skin-related injuries recorded for competitive-level games played on artificial turfs as compared to natural grass fields.

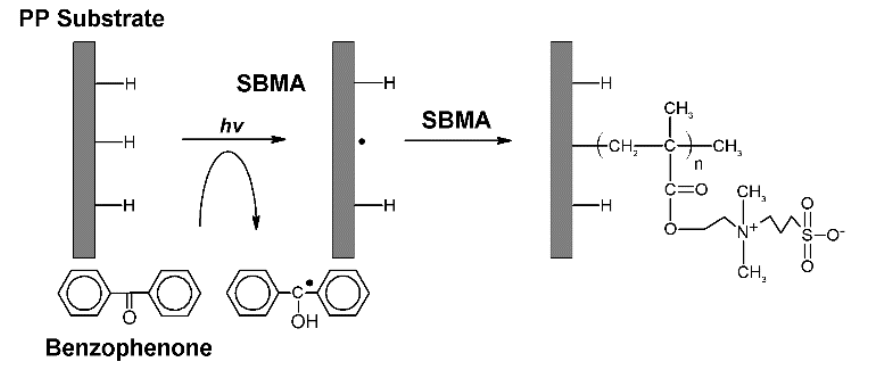

Scheme 1. Schematic of UV-induced surface grafting of pSBMA on PP substrate via free-radical polymerization using $\mathrm{BP}$ as the photoinitiator.

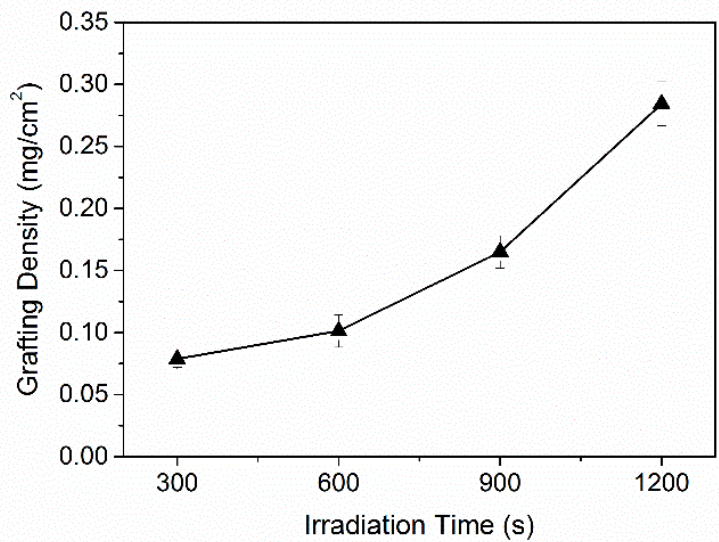

Figure 2. Grafting density of the pSBMA-grafted samples with increasing irradiation duration as determined under dry conditions.
Figure 3. FTIR-ATR transmittance spectra of pSBMA-g-PP samples comparing irradiation durations of (ii) $300 \mathrm{~s}$, (iii) $600 \mathrm{~s}$, (iv) $900 \mathrm{~s}$ and (v) $1200 \mathrm{~s}$ with (i) pristine PP substrate. The inset shows the relative intensity of the characteristic SO peaks $\left(1043 \mathrm{~cm}^{-1}\right)$ to the reference $\mathrm{CH}$ peaks for each sample.
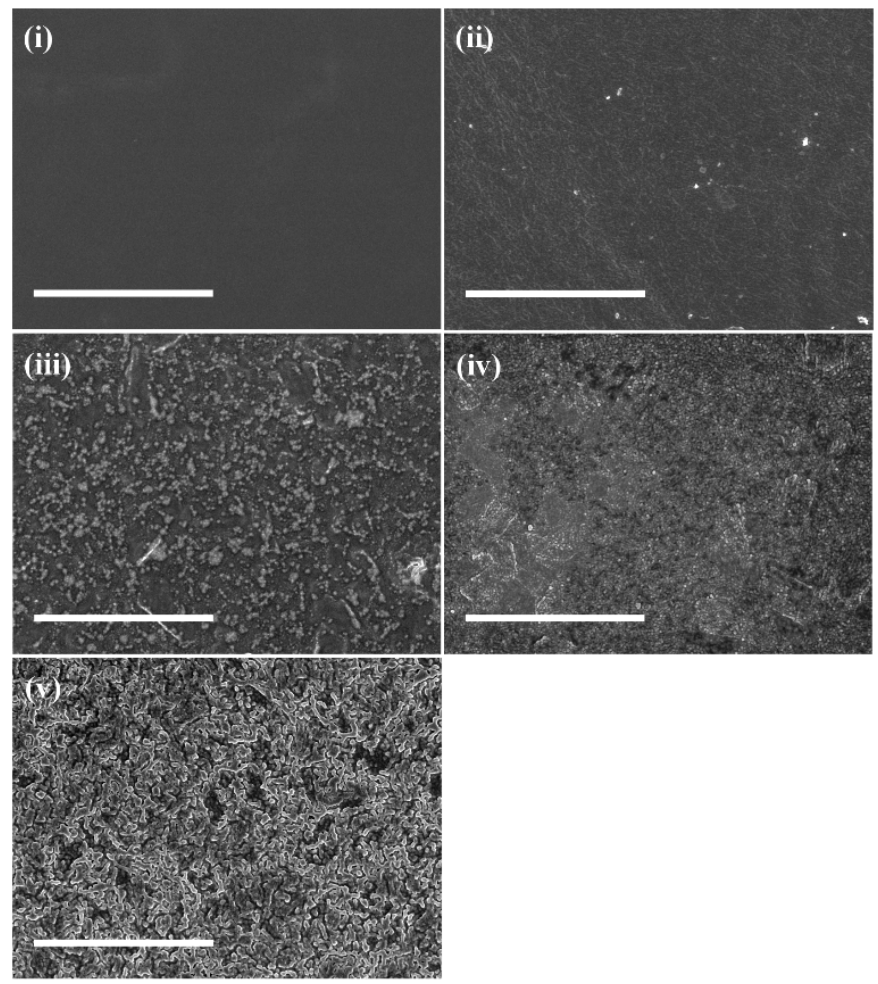

Figure 4. FESEM images of (i) PP substrate and pSBMA-g-PP samples with increasing irradiation durations of $300 \mathrm{~s}$ to $1200 \mathrm{~s}$ (ii) - (v). (the scale bar represents $5 \mu \mathrm{m}$ ) 


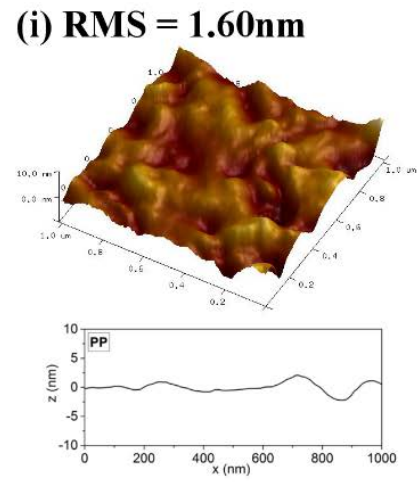

(iii) $\mathrm{RMS}=\mathbf{2 . 5 8 \mathrm { nm }}$
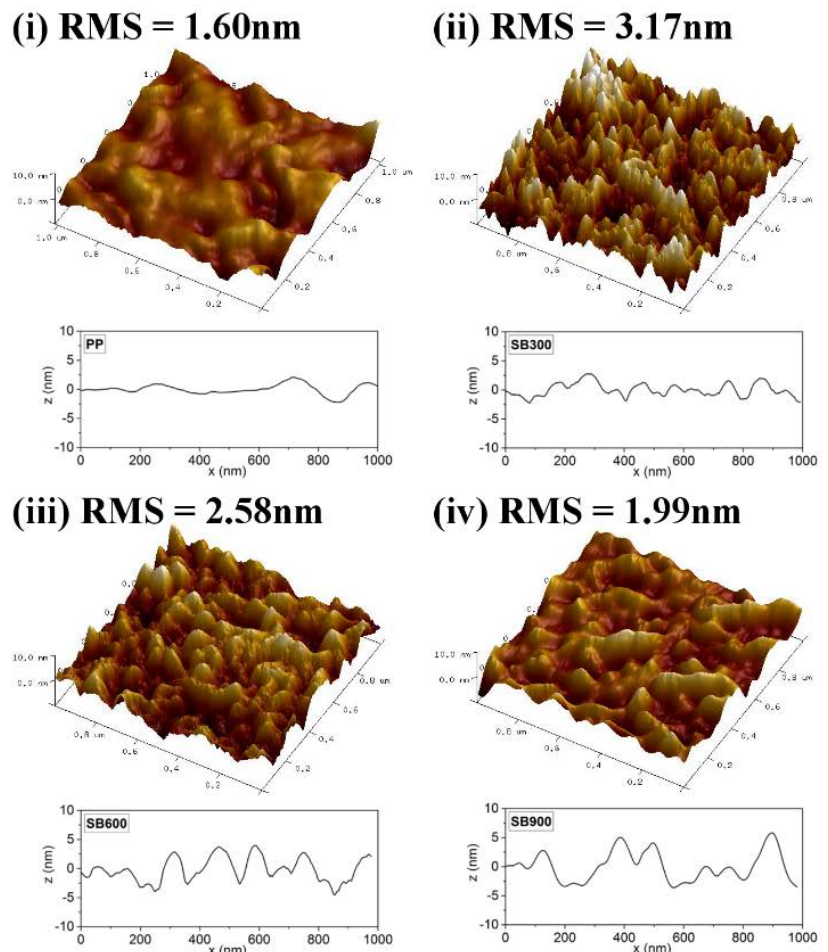

(iv) $R M S=1.99 \mathrm{~nm}$
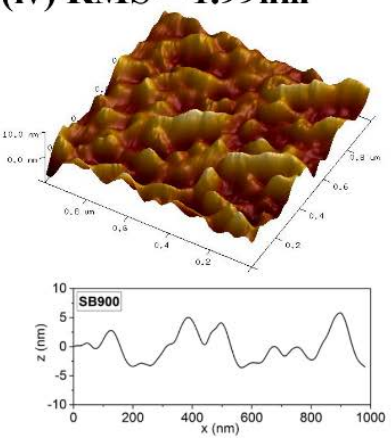

(v) $R M S=2.42 \mathrm{~nm}$
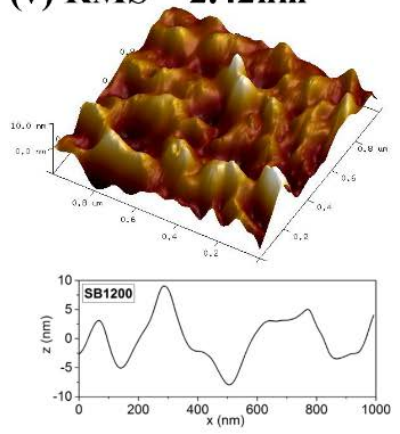

Figure 5. AFM 3D images of (i) PP substrate, and pSBMA-g-PP samples irradiated for (ii) $300 \mathrm{~s}$, (iii) $600 \mathrm{~s}$, (iv) $900 \mathrm{~s}$ and (v) $1200 \mathrm{~s}$. The height scales in the images are at $\pm 10 \mathrm{~nm}$ and the respective root mean square roughness (RMS) of the scanned $1 \mu \mathrm{m}^{2}$ area are also presented. A representative cross-sectional profile of each 3D image is shown.

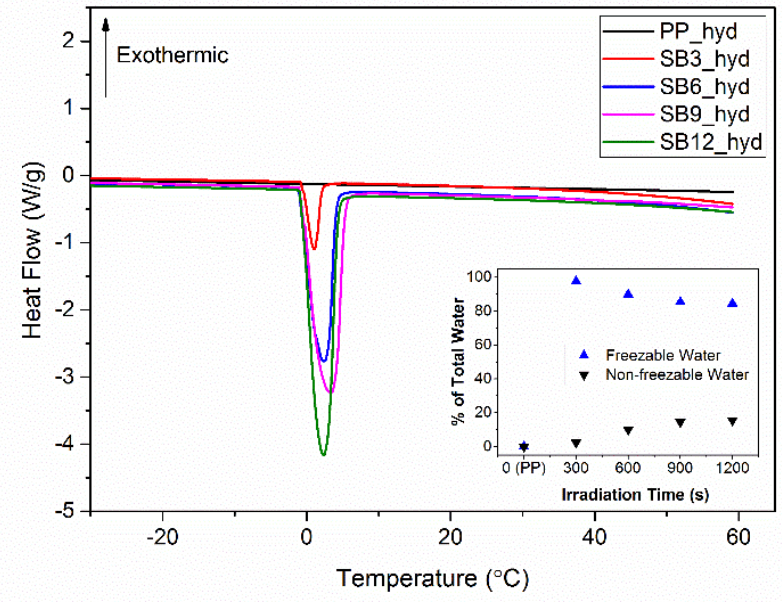

Figure 6. DSC thermogram of the water absorbed onto the respective pSBMAgrafted samples. The inset shows the amount of non-freezable water for each sample as a percentage of the total water absorbed.

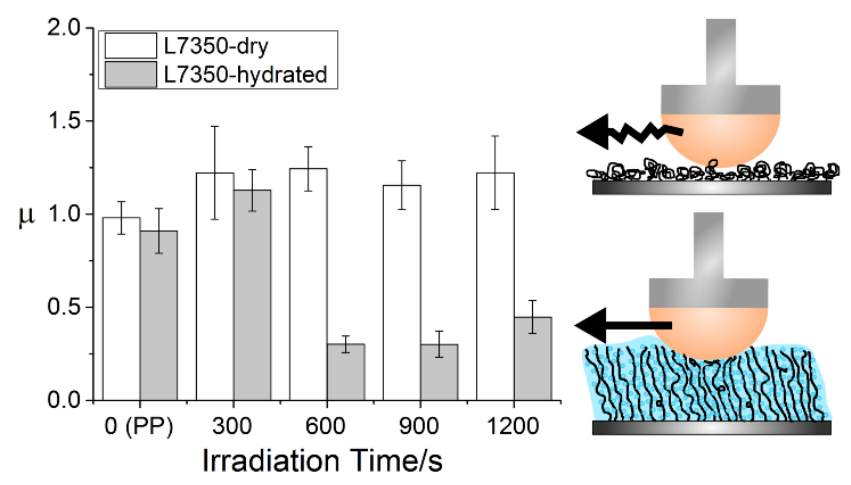

Figure 7. Comparison of $\mu$ values between dry and hydrated samples of PP substrates and pSBMA-g-PP samples against a L7350 silicone skin tribo-tip, in an ambient environment.

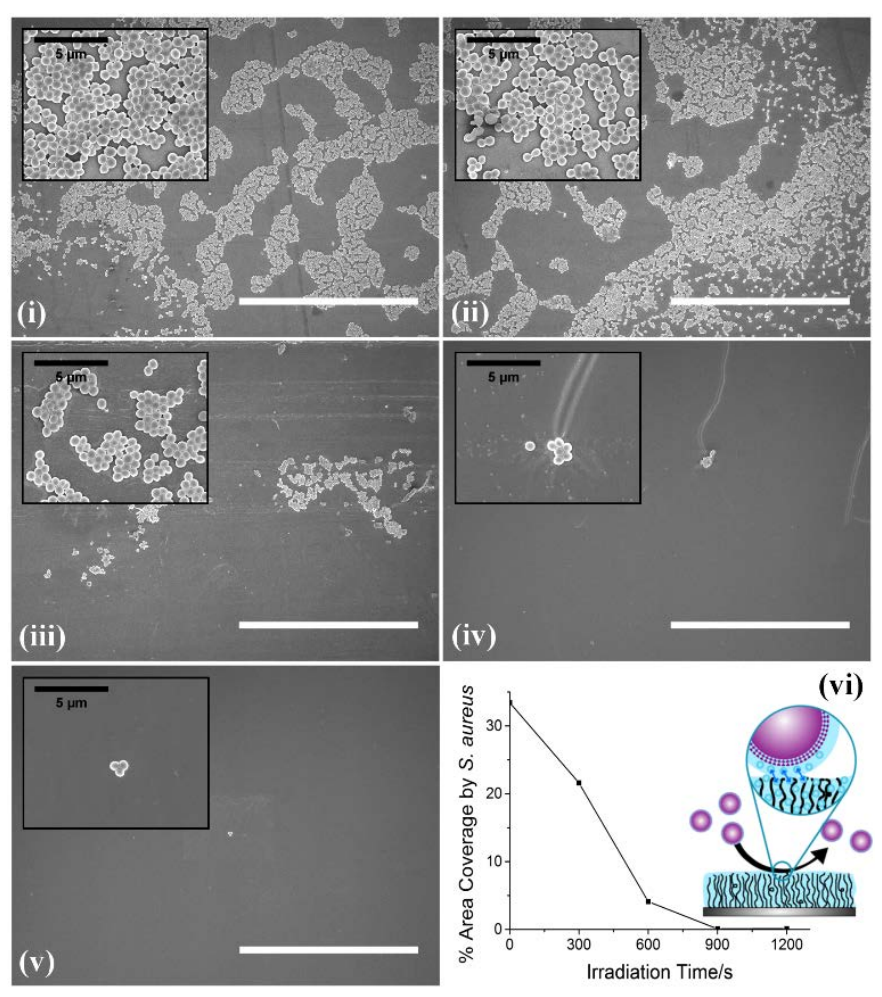

Figure 8. FESEM images of $\mathrm{S}$. aureus cells adsorbed onto pSBMA-g-PP samples of various irradiation durations: (i) $0 \mathrm{~s}$, (ii) $300 \mathrm{~s}$, (iii) $600 \mathrm{~s}$, (iv) $900 \mathrm{~s}$ and (v) $1200 \mathrm{~s}$. (scale bars represent $50 \mu \mathrm{m}$ ) Insets are corresponding bacterial colonies on each sample imaged at $5000 \times$ magnification. (vi) shows the results of surface analysis where the surface fouling by $\mathrm{S}$. aureus cells decreases with increased pSBMA grafting. 